\title{
Drastic corrosive coliation of petroleum oils and the decay of metals
}

\author{
Suresh Aluvihara ${ }^{\mathrm{a}^{*}}$, Jagath K. Premachandra ${ }^{\mathrm{b}}$ \\ ${ }^{a}$ Department of Chemical and Process Engineering, University of Peradeniya, Peradeniya, 20400, \\ Sri Lanka \\ ${ }^{b}$ Department of Chemical and Process Engineering, University of Moratuwa, Katubedda, 10400 \\ Sri Lanka \\ sureshaluvihare@gmail.com
}

Keywords: petroleum oil, corrosive coliation, decay of metals.

In the industry of petroleum oil refining industry the term of corrosion is frequently applicable regarding the several incidents because of the corrosiveness of petroleum oils due to the presence of trace corrosive compounds in such petroleum oils since the occurrences. Usually the corrosion is the results of chemical or electrochemical process of metals when it is exposing to the corrosive environment. The investigations of the impact of the organic acids, salts, elemental sulfur and the Mercaptans on the corrosion rates of seven different types of ferrous metals and the analysis of the nature of the corrosion between these materials were the objectives of the existing research. The relevant corrosive properties of two different types of selected crude oils and the chemical compositions of selected seven different types of ferrous metals were tested by the standard methods and instruments. A batch of similar sized metal coupons was immersed in both crude oil samples separately as three homogeneous metal coupons per each crude oil container. In order of after 15, 30 and 45 days from the immersion the corrosion rates of such metal coupons were determined by the weight loss method as three sets of samples while observing the corroded metal surfaces through an optical microscope. In addition, the decay of ferrous and copper from metals into crude oils while the interaction and the deductions of the initial hardness of metals were tested. As the basic investigations there were observed the relatively lower corrosion rates from stainless steels, relatively higher impact from salts on the metallic corrosion at lower temperatures, formations of $\mathrm{FeS}, \mathrm{Fe}_{2} \mathrm{O}_{3}$, corrosion cracks and pitting, significant decays of ferrous and copper from some metals and the slight reductions of the initial hardness of metals after the interaction with the petroleum oils.

\section{Introduction}

Petroleum oils are the essential compounds that naturally found from the interior part of the earth which are mainly composed with various hydrocarbons and the trace compounds as well. According to the geological formations of such crude oils they may be contained some earth abundant materials as it is, as some 
alterations or secondary compounds. According to the previous studies which have been conducted regarding the corrosiveness of petroleum oils there were investigated some important results regarding the corrosive compounds of petroleum oils especially sulfur and active sulfur compounds, salts and organic acids play a dominant role in the metallic corrosion (Khana et al., 2009; Afaf et al., 2007). According to the theoretical explanations of material engineering the corrosion is defined as the formations of metal oxides, sulfides or hydroxides on the metallic surfaces as a result of either chemical or electrochemical process on the metallic surfaces (Ajimotokan Badmos and Emmanuel 2009; Luther and Rickard 2007; Okoro and Usman, 2015). Usually the corrosive agents may be strong oxidizing agent or corrosive aided environment which is composed with both water and oxygen. The corrosion processes may be varied with the behaviors and the composites in such environment and the chemical compositions of exposing martial to the corrosive environment. By referring the general phenomenon of the corrosion features the corrosion has been categorized into a few of specific types such as the general corrosion (rusty corrosion), galvanic corrosion, thermal corrosion and stress corrosion (Bolton, 1994; Calister, 2003; Khana et al., 2009).

According to the scope of the existing research there were expected to speculate and analyze the impact of two different types of crude oils on the corrosion of seven different types of ferrous metals which are vastly applicable in the industry of petroleum oil refining for several tasks.

\section{Materials and methodology}

By considering the aims, objectives and the availability of providing materials two different types of petroleum oils were selected for the experiments namely as Murban and Das Blend. According to the chemical composition Das Blend is categorized as "sour" crude oil because of the relatively high sulfur content (Fang, Nesic and Young, 2008; Luther and Rickard, 2007). The dominant corrosive properties of both petroleum oils were tested by the standard methods and instruments as discussed in the Table 1.

In addition, seven different types of ferrous metals were selected as the samples to test the corrosion rates with respect to the above selected petroleum oils. The typical applications of such selected ferrous metals in the industry of petroleum oil refining is given in the below.

- Carbon Steel (High) - Transportation tubes, storage tanks

- Carbon Steel (Medium)- Storage tanks, transportation tubes

- Carbon Steel (Mild Steel)- Storage tanks

- 410-MN: 1.8 420-MN: 2.8 (Stainless Steel)Heat exchangers, pre heaters

- 410-MN: 1.7 420-MN: 1.7 (Stainless Steel)Crude distillation columns 
- 321-MN:1.4 304-MN:1.9 (Stainless Steel)Crude distillation columns

- Monel 400- Pre heaters, heat exchangers

Table 1: Test Methodologies for the Selected Corrosive Properties of both Crude Oils

\begin{tabular}{|c|c|c|}
\hline Property & Method & Readings \\
\hline Sulfur content & $\begin{array}{l}\text { Directly used the } \\
\text { crude oil samples to } \\
\text { the XRF analyzer. }\end{array}$ & Direct reading \\
\hline Acidity & $\begin{array}{l}\text { Each sample was } \\
\text { dissolved in a } \\
\text { mixture of toluene } \\
\text { and isopropyl and } \\
\text { titrated with } \\
\text { potassium } \\
\text { hydroxide. }\end{array}$ & End point \\
\hline $\begin{array}{c}\text { Mercaptans } \\
\text { content }\end{array}$ & $\begin{array}{l}\text { Each sample was } \\
\text { dissolved in sodium } \\
\text { acetate and titrated } \\
\text { with silver nitrate. }\end{array}$ & End point \\
\hline Salt content & $\begin{array}{l}\text { Each sample was } \\
\text { dissolved in organic } \\
\text { solvent and exposed } \\
\text { to the cell of } \\
\text { analyzer. }\end{array}$ & Direct reading \\
\hline
\end{tabular}

The chemical compositions of the selected ferrous metals were tested by the XRF detector. According to the working principles of the XRF detector the metallic elemental percentages and some of non metallic elemental compositions of metals are detected excluding the carbon.

A batch of similar sized metal coupons were prepared from the seven selected types of metals as six coupons from each metal type and altogether forty-two metal coupons from all metal types. The surfaces of such metal coupons were well cleaned and the initial weights and the dimensions of each metal coupon were measured by in order of the analytical balance and the micrometer. The prepared metal coupons have been shown in the Figure 1.

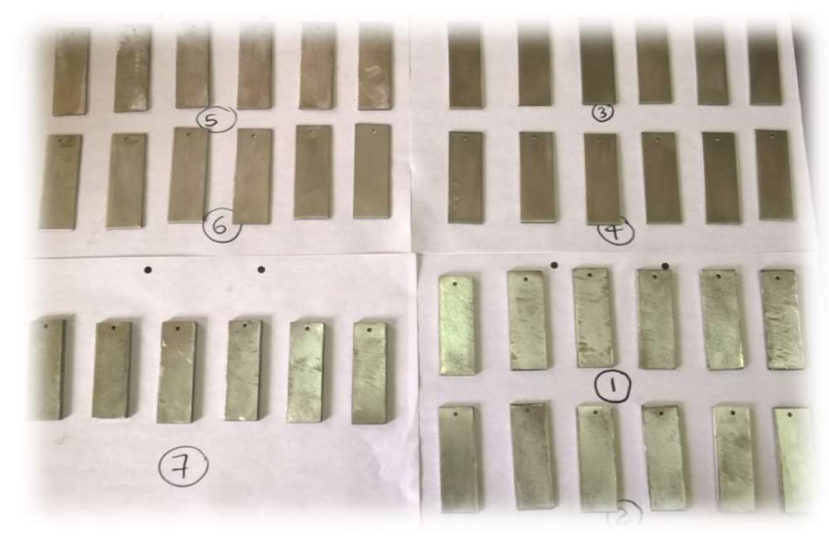

Figure 1: Prepared metals coupons

The prepared metal coupons were immersed in both petroleum oil samples separately as three homogeneous metal coupons for each petroleum oil container as shown in the Figure 2. 

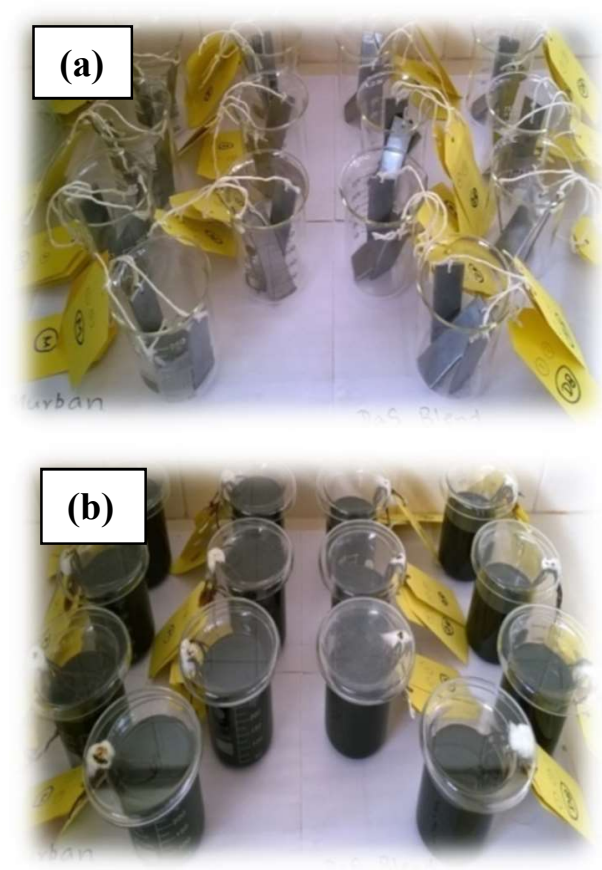

Figure 2: (a-b) Apparatus setup for the experiment

After 15 days from the immersion one coupon from each petroleum oil container was taken out as fourteen metal coupons from all of petroleum oil containers. The corroded metal surfaces of each metal coupon were observed qualitatively through the $400 \mathrm{X}$ lens of an optical microscope and the important observations were identified. The corroded metal surfaces of each metal coupon were cleaned by the sand papers and isooctane and the final weight of each metal coupon was measured by the analytical balance. The corrosion rates of such metal coupons were determined by the weight loss method as explained in the Equation 1 (Afaf et al., 2007; Okpokwasili and Oparaodu, 2014).

$$
\mathrm{CR}=\mathrm{W} * \mathrm{k} /(\mathrm{D} * \mathrm{~A} * \mathrm{t})
$$

Where;

$\mathrm{W}=$ weight loss due to the corrosion in grams $\mathrm{k}=$ constant $(22,300)$
$\mathrm{D}=$ metal density in $\mathrm{g} / \mathrm{cm}^{3}$

$\mathrm{A}=$ area of metal piece $\left(\mathrm{inch}^{2}\right)$

$\mathrm{t}=$ time (days)

$\mathrm{CR}=$ Corrosion rate of metal piece

The similar procedure was repeated for another two similar sets of metal coupons in order of after 30 and 45 days from the immersion for the determination of the corrosion rates of such metal coupons.

The corroded metal surfaces were observed and analyzed through the 400X lens of an optical microscope based on the identification of the corrosion compounds and the nature of such corrosion qualitatively.

In addition, the decayed ferrous and copper concentrations into petroleum oils from metals during the interactions with the petroleum oils were detected by the atomic absorption spectroscopy (AAS). According to the methodology of sample preparation $1 \mathrm{ml}$ of each petroleum oil sample was diluted with $9 \mathrm{ml}$ of 2proponol and filtered.

Finally, the deductions of the initial hardness of metal coupons after exposed to the petroleum oils were measured by the Vicker's hardness tester (Alsahhaf, Elkilani and Fahim, 2010; Bolton, 1994; Hashemi and Smith, 2006; Singh,2006).

Usually it is working with the applied force and the hardness on some particular position is determined by the following equation. 
$\mathrm{HV}=1.854 * \mathrm{P}^{2} / \mathrm{L}^{2}$

Where;

$\mathrm{P}=$ Applied Load on the surface of metal

$\mathrm{L}=$ Diagonal length of square

$\mathrm{HV}=$ Hardness

In the experiment the hardness values of at least three locations on each metal coupon were measured and the average values were interpreted as the hardness.

\section{Results and discussion}

In this section the entirely obtained results have been subdivided into various subsections according to the convenience of the discussion and interpretation.

The obtained results for the analysis of the chemical compositions of selected metals have been interpreted in the Table 2 .

Table 2: Chemical Compositions of the Selected Ferrous Metals

\begin{tabular}{|c|c|c|c|c|c|}
\hline Metal & $\mathrm{Fe}(\%)$ & $\mathrm{Co}(\%)$ & $\mathrm{Ni}(\%)$ & $\mathrm{Cr}(\%)$ & $\mathrm{Cu}(\%)$ \\
\hline (1)Carbon Steel (High) & 98.60 & - & 0.17 & 0.14 & 0.37 \\
\hline (2)Carbon Steel (Medium) & 99.36 & - & - & - & - \\
\hline $\begin{array}{l}\text { (3) Carbon Steel } \\
\text { (Mild Steel) }\end{array}$ & 99.46 & $<0.30$ & - & $<0.07$ & - \\
\hline $\begin{array}{c}\text { (4) 410-MN: } 1.8 \text { 420-MN: } 2.8 \\
\text { (Stainless Steel) }\end{array}$ & 88.25 & - & 0.18 & 10.92 & 0.10 \\
\hline $\begin{array}{c}\text { (5) 410-MN: } 1.7 \text { 420-MN: } 1.7 \\
\text { (Stainless Steel) }\end{array}$ & 87.44 & - & - & 11.99 & - \\
\hline $\begin{array}{c}\text { (6) 321-MN:1.4 304-MN:1.9 } \\
\text { (Stainless Steel) }\end{array}$ & 72.47 & - & 8.65 & 17.14 & - \\
\hline (7)Monel 400 & 1.40 & 0.11 & 64.36 & $<0.04$ & 33.29 \\
\hline
\end{tabular}

As the summary of above results there can be shortlisted the relatively higher ferrous concentrations in carbon steels, relatively lower ferrous concentrations in stainless steels and intermediate ferrous concentrations in Monel metal. As the distinguishing observations regarding the chemical compositions of ferrous metals that there were observed the relatively higher amounts of trace elements in stainless steels such as the nickel and chromium. Especially the doping of trace elements with the ferrous metals is done based on the satisfaction of a few of enhancements of those metals such as the increments of the strength, hardness and the reductions of the corrosive tendency (Calister, 2003; Davis and Davis, 2003; Hashemi and Smith, 2006; Khana et al., 2009). 
The obtained results for the analysis of the corrosive compounds in both crude oils have been interpreted in the Table 3.

Table 3: Corrosive Composites of both Crude Oils organic acids react with the metals according to the following chemical reaction and the major outcome is FeS (Bota, Nesic, Qu, and Wolf, 2010; Calister, 2003; Speight, 1999).

\begin{tabular}{lll}
\hline Property & Murban & Das Blend \\
\hline Sulfur content (Wt. \%) & 0.758 & 1.135 \\
Salt content (ptb) & 4.4 & 3.6 \\
Acidity (mg KOH/g) & 0.01 & 0.02 \\
Mercaptans content (ppm) & 25 & 56
\end{tabular}

$\mathrm{Fe}+2 \mathrm{RCOOH} \rightarrow \mathrm{Fe}(\mathrm{RCOO}) 2+\mathrm{H} 2$

$\mathrm{FeS}+2 \mathrm{RCOOH} \rightarrow \mathrm{Fe}(\mathrm{COOR}) 2+\mathrm{H} 2 \mathrm{~S}$$$
\mathrm{Fe}(\mathrm{COOR}) 2+\mathrm{H} 2 \mathrm{~S} \rightarrow \mathrm{FeS}+2 \mathrm{RCOOH}
$$

Salts are the considerable corrosive compounds that found in crude oils since the

By referring the obtained results for the dominant corrosive compounds of both Murban and Das Blend crude oils that mainly it was found the higher amount of salts from Murban crude oil since obtaining relatively higher amounts of organic acids, elemental sulfur and Mercaptans amounts from Das Blend crude oil which are considering as some foremost compounds in various conditions. The real impact of such compounds is possible to discuss separately with their chemical reaction mechanisms with supportive conditions.

The organic acids are the mostly found corrosive compounds in crude oils also known as "naphthenic acids" in some of reference materials which are having the universal chemical formula of "RCOOH". The total amount of such acids presence in some particular crude oil is known as the acidity or total acid number (TAN) of that crude oil and also the acidity is a measurable parameter. Usually such occurrence because of the water solubility of such salts as the forms of $\mathrm{NaCl}, \mathrm{MgCl}_{2}$, and $\mathrm{CaCl} 2$. The term that the salt content of some crude oil indicates the summation of such salts presence in the relevant crude oil. At the higher temperatures such salts tend to be broken into $\mathrm{HCl}$ molecules even though never been found any corrosiveness from such molecules at higher temperatures. But when the system is approaching towards the lower temperatures such $\mathrm{HCl}$ molecules are reacted with the water or moisture presence in crude oils and ultimately produce highly corrosive hydrochloric acids. Also during the process, the formations of the hydrogen sulfide cause the corrosion and formed the FeS on the metallic surfaces (Alsahhaf, Elkilani and Fahim, 2010; Davis and Davis, 2003). The chemical reaction mechanism of the salts and metals are given in the below.

$$
\begin{aligned}
& \mathrm{CaCl} 2+\mathrm{H} 2 \mathrm{O} \rightarrow \mathrm{CaO}+2 \mathrm{HCl} \\
& \mathrm{HCl}+\mathrm{Fe} \rightarrow \mathrm{FeCl} 2+\mathrm{H} 2
\end{aligned}
$$




$$
\mathrm{H} 2+\mathrm{S} \rightarrow \mathrm{H} 2 \mathrm{~S}
$$

$\mathrm{FeCl} 2+\mathrm{H} 2 \mathrm{~S} \rightarrow \mathrm{FeS}+2 \mathrm{HCl}$

Sulfur and active forms of sulfur compounds are the foremost corrosive compounds under various conditions as found most of relevant results of previous researches. According to the chemical compositions of the earth mantle sulfur is an abundant element in the interior part of the earth. Especially in the case of corrosion of metals with respect to the sulfur and active sulfur compounds there are some different process due to the variations of such sulfur compounds and the reactivity of attached functional groups with sulfur atoms such as hydrogen sulfides, thiophenes, sulfoxides and Mercaptans. The corrosion process due to the effect of elemental sulfur is known as the "localized corrosion" which is occurring properly at the temperature about $80^{\circ} \mathrm{C}$ (Fang, Nesic, and Young, 2008; Luther and Rickard, 2007; Okoro and Usman, 2015). Also the corrosion process due to the Mercaptans is known as the "sulfidation" which is also occurring properly at about $230^{\circ} \mathrm{C}$. The general chemical reactions for above chemical processes are given in the chemical reaction series below.

$$
\begin{aligned}
& \mathrm{S} 8(\mathrm{~s})+8 \mathrm{H} 2 \mathrm{O}(\mathrm{l}) \rightarrow \\
& \quad 6 \mathrm{H} 2 \mathrm{~S}(\mathrm{aq})+2 \mathrm{H} 2 \mathrm{SO} 4(\mathrm{aq}) \\
& 8 \mathrm{Fe}+\mathrm{S} 8 \rightarrow \quad 8 \mathrm{FeS}
\end{aligned}
$$

The obtained results for the corrosion rates of metals with respect to both Murban and

\begin{tabular}{|c|c|c|c|c|}
\hline Metal & $\begin{array}{c}\text { Corrosion Rate after } \\
15 \text { Days } \\
\left(\mathrm{cm}^{3} \text { inch }^{-1} \text { day }^{-1}\right)\end{array}$ & $\begin{array}{c}\text { Corrosion Rate after } \\
30 \text { Days } \\
\left(\mathrm{cm}^{3} \text { inch }^{-1} \text { day }^{-1}\right)\end{array}$ & $\begin{array}{c}\text { Corrosion Rate after } \\
45 \text { Days } \\
\left(\mathrm{cm}^{3} \text { inch }^{-1} \text { day }^{-1}\right)\end{array}$ & $\begin{array}{c}\text { Average Corrosion } \\
\text { Rate } \\
\left(\mathrm{cm}^{3} \text { inch }^{-1} \text { day }^{-1}\right)\end{array}$ \\
\hline $\begin{array}{c}\text { (1)Carbon Steel } \\
\text { (High) }\end{array}$ & 0.811971 & 0.466425 & 0.068794 & 0.4490632 \\
\hline $\begin{array}{l}\text { (2)Carbon Steel } \\
\text { (Medium) }\end{array}$ & 0.817791 & 0.180339 & 0.073358 & 0.3571623 \\
\hline $\begin{array}{l}\text { (3) Carbon Steel } \\
\text { (Mild Steel) }\end{array}$ & 0.10973 & 0.048244 & 0.038592 & 0.0655217 \\
\hline $\begin{array}{l}\text { (4) 410-MN: } 1.8 \\
\text { 420-MN: } 2.8 \\
\text { (Stainless Steel) }\end{array}$ & 0.041784 & 0.016075 & 0.011801 & 0.02322 \\
\hline $\begin{array}{c}\text { (5) 410-MN:1.7 } \\
\text { 420-MN: } 1.7 \\
\text { (Stainless Steel) }\end{array}$ & 0.11626 & 0.011968 & 0.007574 & 0.0452676 \\
\hline
\end{tabular}
Das Blend crude oils after certain immersion periods are shortlisted in the Table 4 and Table 5.

Table 4: Corrosion Rates of Metals in Murban Crude Oils 
Table 5: Corrosion rates of metals in Das Blend crude oils

\begin{tabular}{|c|c|c|c|c|}
\hline Metal & $\begin{array}{l}\text { Corrosion Rate } \\
\text { after 15 Days } \\
\left(\mathrm{cm}^{3} \text { inch }^{-1} \text { day }^{-1}\right)\end{array}$ & $\begin{array}{l}\text { Corrosion Rate } \\
\text { after } 30 \text { Days } \\
\left(\mathrm{cm}^{3} \text { inch }^{-1} \text { day }^{-1}\right)\end{array}$ & $\begin{array}{l}\text { Corrosion Rate } \\
\text { after 45 Days } \\
\left(\mathrm{cm}^{3} \text { inch }^{-1} \text { day }^{-1}\right)\end{array}$ & $\begin{array}{c}\text { Average Corrosion } \\
\text { Rat e }^{-1} \\
\left(\mathrm{~cm}^{3} \text { inch }^{-1} \text { day }^{-1}\right)\end{array}$ \\
\hline $\begin{array}{l}\text { (1)Carbon Steel } \\
\text { (High) }\end{array}$ & 0.350249 & 0.224901 & 0.024738 & 0.1999627 \\
\hline $\begin{array}{l}\text { (2)Carbon Steel } \\
\text { (Medium) }\end{array}$ & 0.481055 & 0.140654 & 0.05911 & 0.2269396 \\
\hline $\begin{array}{l}\text { (3) Carbon Steel } \\
\text { (Mild Steel) }\end{array}$ & 0.162883 & 0.141093 & 0.100635 & 0.1348702 \\
\hline $\begin{array}{c}\text { (4) 410-MN: } 1.8420-\mathrm{MN}: 2.8 \\
\text { (Stainless Steel) }\end{array}$ & 0.044146 & 0.034035 & 0.006149 & 0.0281102 \\
\hline $\begin{array}{c}\text { (5) 410-MN: } 1.7420-\mathrm{MN}: 1.7 \\
\text { (Stainless Steel) }\end{array}$ & 0.053701 & 0.034841 & 0.016363 & 0.0349681 \\
\hline $\begin{array}{c}\text { (6) 321-MN:1.4 304-MN:1.9 } \\
\text { (Stainless Steel) }\end{array}$ & 0.022894 & 0.006503 & 0.002825 & 0.0107404 \\
\hline (7)Monel 400 & 0.061554 & 0.037655 & 0.016067 & 0.0384254 \\
\hline
\end{tabular}

The corrosion rates of metals after certain immersion periods of 15,30 and 45 days in both crude oils have been graphically represented in the Figure 3 and Figure 4.

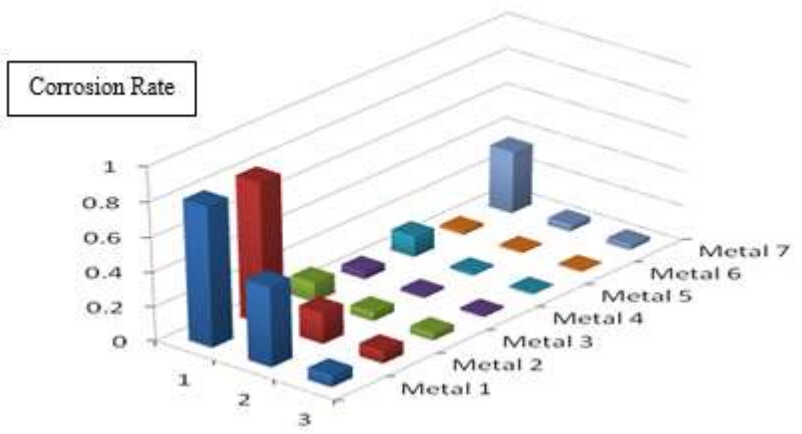

Figure 3: Corrosion rates of metals in Murban crude oil after certain immersion periods

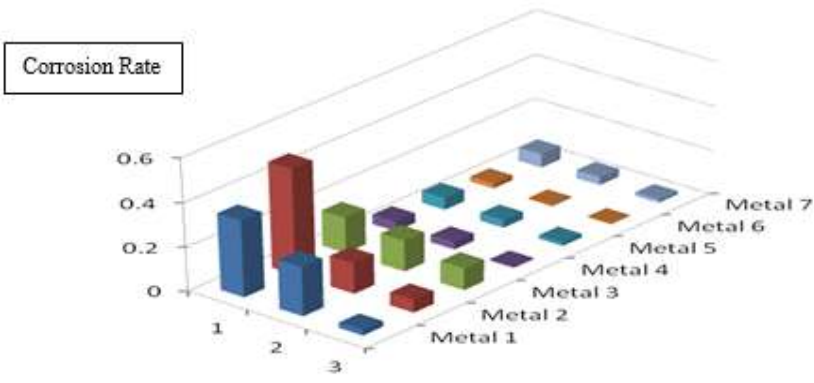

Figure 4: Corrosion rates of metals in Das Blend crude oil after certain immersion periods

A summarized graphical representation of the average corrosion rates of above metals with respect to both crude oils are shown in the Figure 5. 


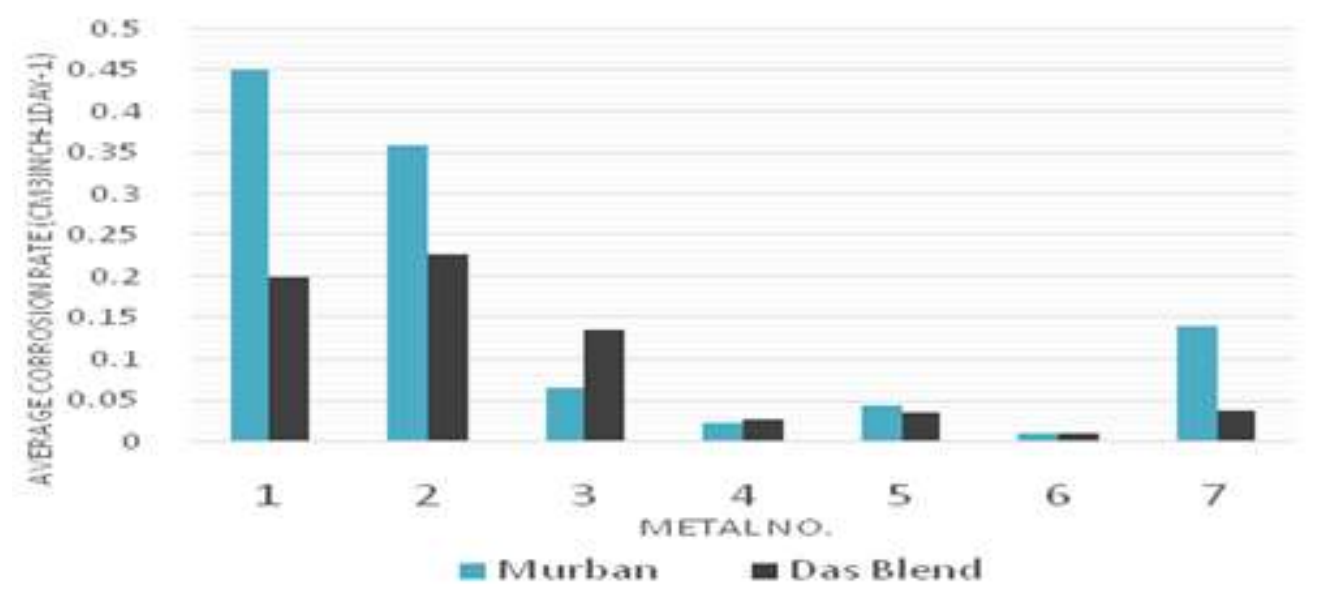

Figure 5: Average corrosion rates of metals in both crude oils

By referring the distribution of the corrosion rates of seven different types of metals (Figure 3, Figure 4 and Figure 5) that there can be observed relatively higher corrosion rates from carbon steels in both crude oils, moderate corrosion rates from mild steels and Monel metal and least corrosion rates from stainless steels as usual. When considering the corrosion rates of stainless steels with their chemical compositions especially the least corrosion rates were observed from 321-MN: 1.4 304-MN: 1.9 (Stainless Steel) which is having $\sim 18 \%$ of chromium and $\sim 8 \%$ nickel. According to the theoretical explanation of the corrosive protection of stainless steels the combination of at least $12 \%$ of chromium with sufficient amounts of nickel is the essential factor (Calister, 2003; Davis and Davis, 2003; Hashemi and Smith, 2006; Khana et al., 2009).

In the considerations of the impacts of the corrosive compounds of both crude oils on the corrosion rates of metals, four types of metals showed their corrosion rates in Murban crude oils since other three types of metals were shown their higher corrosion rates in Das Blend crude oils. When comparing with the corrosive properties of both crude oils that there can be seen some higher impact from salts on the metallic corrosion comparatively. But it is better to recommend also some advanced corrosion rate determination method to be performed simultaneously with the weight loss method for more accurate results.

The variations of the corrosion rates of metal $\mathrm{s}$ with the exposure time periods with respect to both crude oils have been interpreted in the Figure 6 and Figure 7.

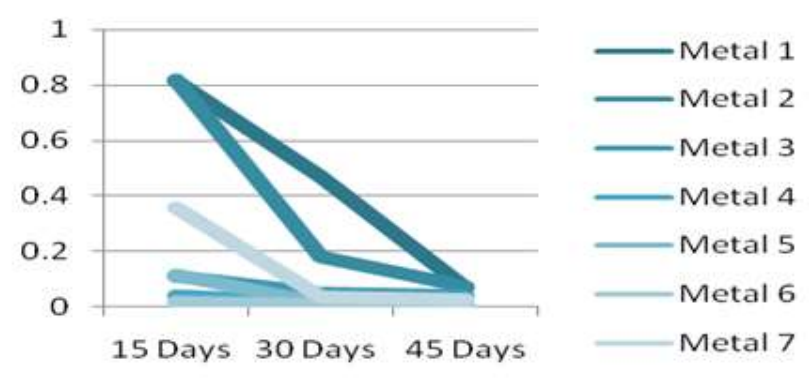

Figure 6: Variations of the corrosion rates of metals with the exposure time in Murban 


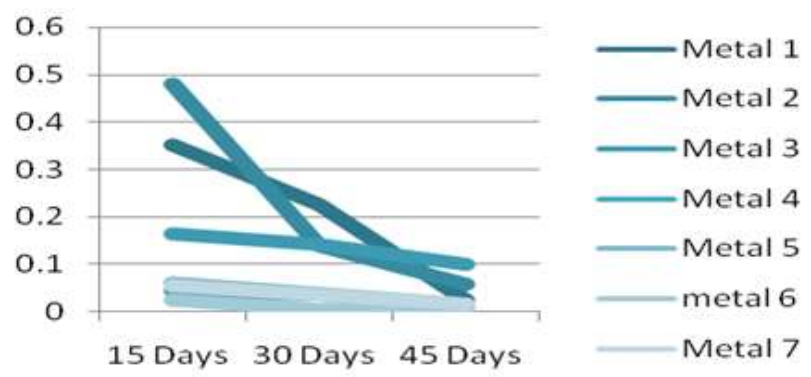

Figure 7: Variations of the corrosion rates of metals with the exposure time in Das Blend.
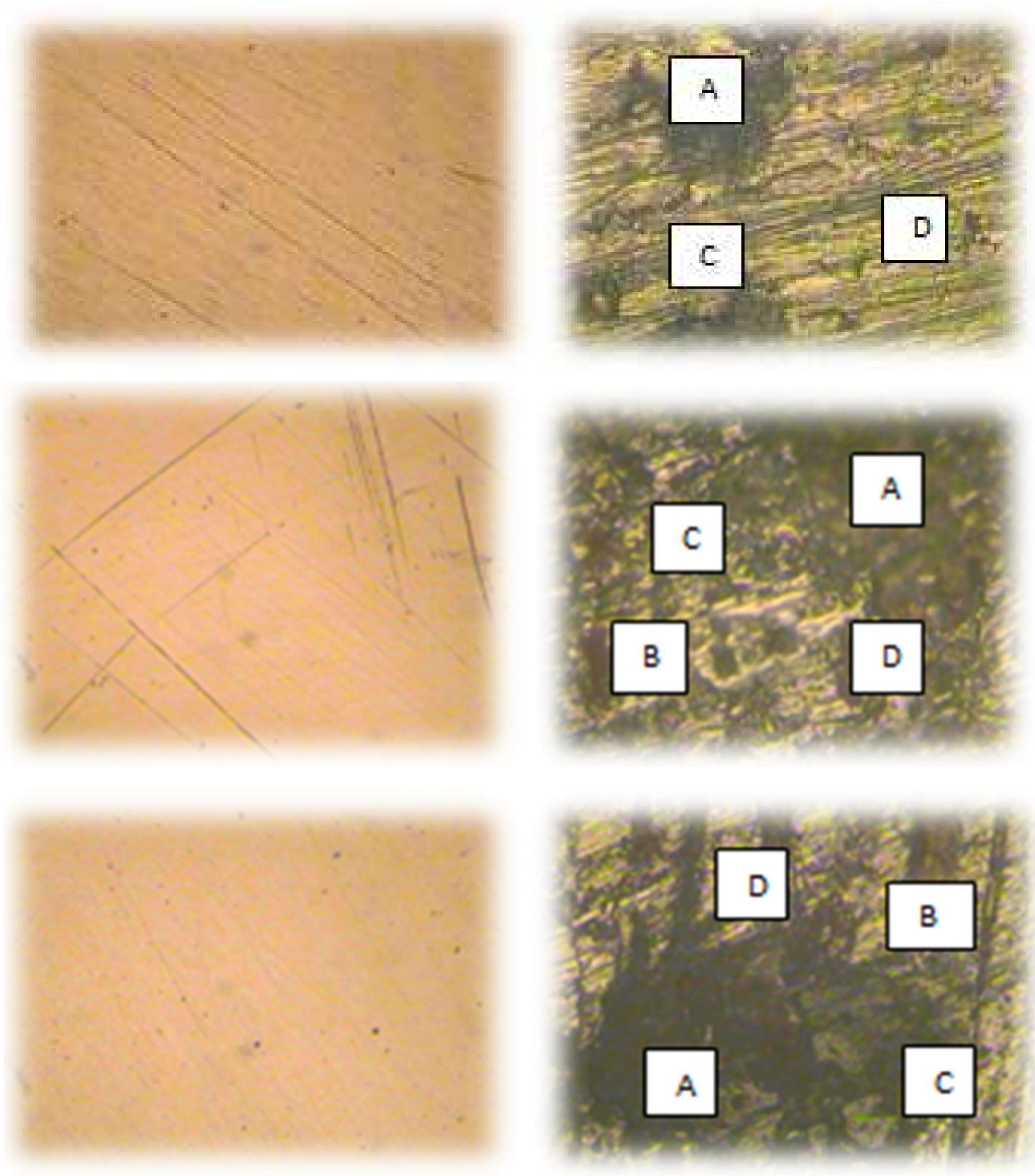

Figure 8: Corroded surfaces of some of metals

The above variations (Figure 6 and Figure 7) accordance to the inversely proportional showed the similar distributions of the corrosion relationship between the exposure time and the rates of metals with the exposure time period that corrosion rates in the equation of weight loss 
method (Afaf et al., 2007; Okpokwasili and Oparaodu, 2014). Therefore, the observations showed the independency and accuracy of weight loss method with respect to any type of metal forever.

According to the observed results for the microscopic analysis of the corroded metals surfaces some kind of special observations were identified qualitatively. The distinguished observations have been highlighted in the Figure 8.

In the microscopic analysis of the corroded metal surfaces of the metals, there were observed some important visible features which are important in the explanation and confirmation of the formed corrosion compounds although the microscopic analysis is not applicable alone to conclude exactly the nature of corrosion compound. The following discussion was done only considering the basic features of the common corrosion compounds and the existing investigation must be altered for descriptive and more accurate conclusion.

According to the existing qualitative analysis of the corroded metal surfaces there were identified a few of corrosion compounds only with the visible appearances foremost of the color (Figure 8). The specific compounds are given in the below.

- A- Ferrous Sulfides

- B- Ferrous Oxides

- C-Corrosion Cracks

- D- Cavities/ Pitting Corrosion

The explanation between the observations and the absolute properties of such corrosion compounds have been given in the Table 6 (Calister, 2003; Davis and Davis, 2003; Hashemi and Smith, 2006; Khana et al., 2009).

Table 6: Physical appearances of corrosion compounds

\begin{tabular}{|c|c|c|}
\hline Compound & Appearances & Observations \\
\hline $\mathrm{FeS}$ & $\begin{array}{c}\text { Black, brownish black, property } \\
\text { of powder, pitting, cracks }\end{array}$ & $\begin{array}{l}\text { Observed most of features in each } \\
\text { metal piece. }\end{array}$ \\
\hline $\mathrm{Fe}_{2} \mathrm{O}_{3}$ & Rusty color & Observed rarely. \\
\hline $\mathrm{CuS}$ & $\begin{array}{c}\text { Dark indigo/ dark blue, property } \\
\text { of powder }\end{array}$ & Unable to specify. \\
\hline
\end{tabular}

When considering both observations and theoretical explanation of such corrosion compounds mostly found the formations of the ferrous sulfides, rarely ferrous oxides, corrosion cracks and some cavities together on the metal surfaces. As a special observation that there were observed some black color compound on the corroded surfaces of Monel metal which is having relatively higher amount of copper and trace amount of ferrous. According to the 
physical properties of $\mathrm{CuS}$ that it can be assumed as $\mathrm{CuS}$ although it is impossible to distinguish

that one is exactly $\mathrm{CuS}$ only with the qualitative analysis and furthermore it is better to recommend some compositional analysis of corrosion compounds by using advanced analytical methods for the better analysis and results for future researches and experiments (Calister, 2003; Davis and Davis, 2003; Hashemi and Smith, 2006; Khana et al., 2009; Singh, 2006).

As the further recommendation of the compositional analysis of the corrosion compounds, the following analytical techniques are widely used in the research works.

- X-ray diffraction (XRD) - Especially applicable in the investigation of crystalline structure

- Scanning electron microscope (SEM) Applicable in the surface analysis of metals, polymers and composites

- Scanning tunneling microscope (STM) or atomic force microscope (AFM) - Analysis of the material surfaces in nano-scale
- X-ray photo emission spectroscopy (XPS) Qualitative identification of composed elements in a sample

The obtained results for the experiments of the analysis of decayed ferrous and copper concentrations from metals into crude oils have been presented in the Table 7 .

By referring the obtained results for the decayed metal concentrations in to crude oils mainly there can be concluded the significant decay of copper from Monel metal which is having relatively higher amount of copper, relatively higher decays of ferrous from carbon steels and lack of any decay of ferrous from any kind of stainless steel into crude oils. When comparing with the theoretical explanations that the removal of corrosion compounds from the metallic surfaces due to the effects of attractive and repulsive forces in between the successive electrons and protons is possible to emphasize the nearest reason for the decay of some metallic elements in to crude oils (Calister, 2003; Davis and Davis, 2003; Hashemi and Smith, 2006; Khana et al., 2009; Singh,2006).

The variations of the initial hardness of metal coupons after interactions with both Murban and Das Blend petroleum oils have been shown in order of the Figure 11 and Figure 12. 
Table 7: Decayed ferrous and copper concentrations from metals into crude oils

\begin{tabular}{cccc}
\hline Metal & Crude Oil & Fe Concentration $/ \mathrm{ppm}$ & $\mathrm{Cu}$ Concentration $/ \mathrm{ppm}$ \\
\hline Carbon Steel & Murban & 0.47 & - \\
(High) & Das Blend & 1.10 & - \\
Carbon Steel & Murban & 0.54 & - \\
(Medium) & Das Blend & 0.02 & - \\
Carbon Steel & Murban & -0.08 & - \\
(Mild Steel) & Das Blend & -0.48 & - \\
410-MN: 1.8 & Murban & -0.65 & - \\
$420-$ MN: 2.8 & Das Blend & -0.78 & - \\
(Stainless Steel) & & & - \\
$410-M N: 1.7$ & Murban & -0.71 & - \\
$420-M N: 1.7$ & Das Blend & -0.79 & - \\
(Stainless Steel) & & & \\
321-MN:1.4 & Murban & -0.44 & 10.47 \\
304-MN:1.9 & Das Blend & -0.17 & 9.49 \\
(Stainless Steel) & & & \\
Monel 400 & Murban & - & - \\
& Das Blend & - & \\
\hline
\end{tabular}

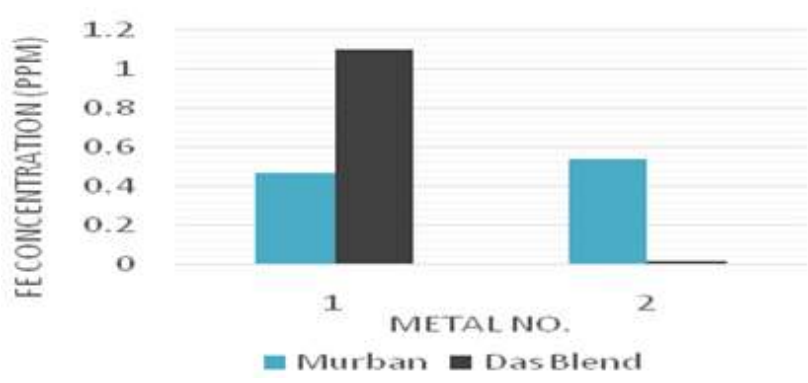

Figure 9: Decayed ferrous concentrations from metals

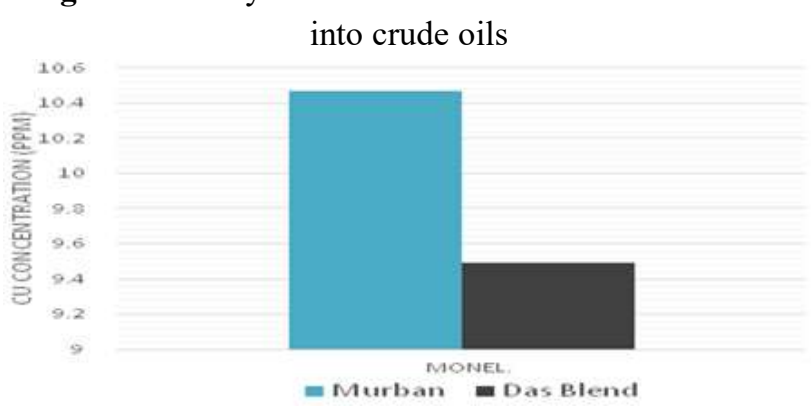

Figure 10: Decayed copper concentrations from metals into crude oils

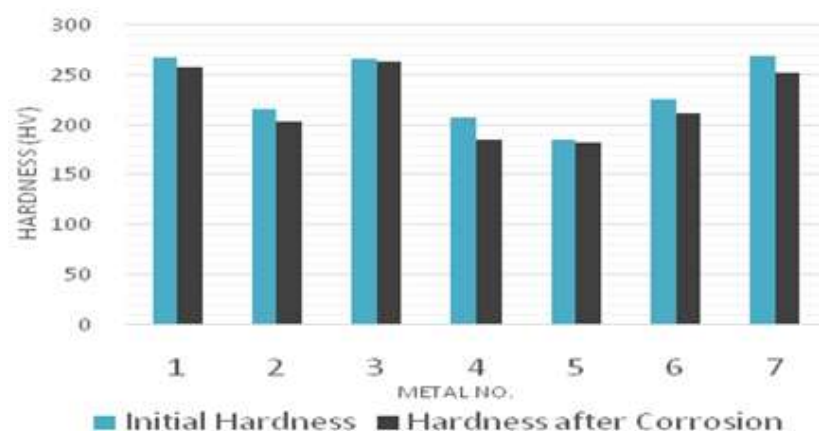

Figure 11: Deductions of the initial hardness of metal coupons in Murban

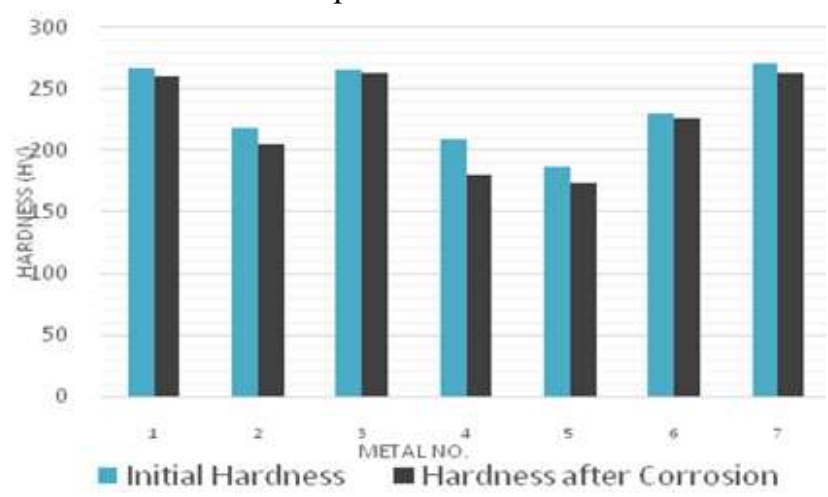

Figure 12: Deductions of the initial hardness of metal coupons in Das Blend 
When comparing the obtained results for the initial and final hardness of most of metal coupons (Figure 12 and Figure 13) that there were observed the slight reductions of the initial hardness of metal coupons after interactions with the petroleum oils. Usually after the formations of the heterogeneous corrosion compounds on the metal surfaces such compounds may have less stability on the metal surfaces for no longer retention time while generating some unstable conditions on the metal surfaces. The phenomenon that reductions of the initial hardness is possible to explained with that theoretical concept and also adequate to use as an evidence for the formations of the corrosion compounds on the metal surfaces. In the further analysis of the obtained results that there were unable to observe any regular sequence of the variation of corrosion rates with respect to other parameters or even the type of metal since it was observed only slight reduction of the hardness (Calister, 2003; Davis and Davis, 2003; Hashemi and Smith, 2006; Khana et al., 2009; Singh, 2006).

\section{Conclusions}

As the outcomes of the existing research basically there were obtained the relatively lower corrosion rates from stainless steels especially having the chemical compositions of at least $12 \%$ of chromium with sufficient amounts of nickel because of the self corrosion protection film of stainless steels with the combinations of both nickel and chromium, the relatively higher impact from slats on the metallic corrosion when comparing with other corrosive composites although less progress of the corrosion process of "sulfidation" and "localized corrosion" in the lower temperatures, formations of $\mathrm{FeS}, \mathrm{Fe}_{2} \mathrm{O}_{3}$, corrosion cracks and the cavities on the metal surfaces, significant decay of ferrous from carbon steels, lack of any ferrous decay from any stainless steel, relatively massive decay of copper from Monel metal into petroleum oils and the slight reductions of the initial hardness of most for metals after formations of the corrosion on such metal surfaces.

\section{Acknowledgements}

The research was facilitated by the Ceylon Petroleum Cooperation, University of Moratuwa and Uva Wellassa University, Sri Lanka.

\section{References}

[1] Afaf, G. A., 2007, Corrosion Treatment of High TAN Crude, PhD. Thesis, University of Khartoum, Khartoum, Sudan.

[2] Ahmed I.M., Elnour M.M. and Ibrahim M.T., 2014, Study the Effects of Naphthenic Acid in Crude Oil Equipment Corrosion, Journal of Applied and Industrial Sciences, 2, 6, 255-260.

[3] Ajimotokan, H. A., Badmos, A. Y. and Emmanuel, E. O., 2009, Corrosion in Petroleum Pipelines, New York Science Journal, 2, 5, 36-40.

[4] Alsahhaf, T.A., Elkilani, A. and Fahim, M.A., 2010 Fundamentals of Petroleum Refining, Radarweg Press: Amsterdam, The Netherland.

[5] Bolton, W., 1994., Engineering Materials Technology, B. H Newnes Limited: London, UK.

[6] Bota, G. M., Nesic, S., Qu, D. and Wolf, H.A., 2010, Naphthenic Acid Corrosion of Mild Steel in the 
Presence of Sulfide Scales Formed in Crude Oil

Fractions at High Temperature, presented at International Corrosion Conference and Expo.

[7] Calister, W. D., 2003, An Introduction of Materials Science and Engineering, John Wiley and Sons Inc.: New York, USA.

[8] Davis, M.E. and Davis, R.J., 2003, Fundamentals of Chemical Reaction Engineering, McGraw-Hill: New York, USA.

[9] Fang, H., Nesic, S. and Young, D., 2008, Corrosion of Mild Steel in the Presence of Elemental Sulfur, presented at International Corrosion Conference and Expo.

[10] Hashemi, J., and Smith, W.F., 2006, Foundations of Material Science and Engineering, $4^{\text {th }}$ Ed.: McGrawHill: New York, USA.

[11] Hassan, N. S., 2013, The Effect of Different Operating Parameters on the Corrosion Rate of Carbon Steel in Petroleum Fractions, Engineering and Technology Journal, 31, A, 1182- 1193.

[12] Khana, O.P., 2009, Materials Science and Metallurgy, Dhanpet Rai and Sons publication: New Delhi, India.

[13] Luther, G.W. and Rickard, D., 2007, Chemistry of Iron Sulfides, Chemical Reviews, 107, 2, 514-562.

[14] Muller, M., 1982, Theoretical Considerations on Corrosion Fatigue Crack Initiation, Metallurgical Transactions, 13, 649-655.

[15] Okoro, L.N. and Usman, A.D., 2015, Mild Steel Corrosion in Different Oil Types, International Journal of Scientific Research and Innovative Technology, 2, 2, 9-13.

[16] Okpokwasili, G. C. and Oparaodu, K. O., 2014, Comparison of Percentage Weight Loss and Corrosion Rate Trends in Different Metal Coupons from two Soil Environments, International Journal of Environmental Bioremediation \& Biodegradation, 2, $5,243-249$.
[17] Singh R.,2006, Introduction to Basic Manufacturing Process and Engineering Workshop, New Age International Publication: New Delhi, India.

[18] Speight, J.G.,1999, The Chemistry and Technology of Petroleum, Marcel Dekker: New York, USA. 